This article has been scanned by iThenticat No plagiarism detected

Volume 3, Issue 5, October 2021

p. $142-151$

\title{
THE EFFECTIVENESS GEOGEBRA ON SOFTWARE IN TEACHING " SPACE
} GEOMETRY ACHIEVEMENT OF ELEVENTH GRADE"

http://dx.doi.org/10.47832/2757-5403.5-3.13

Salim Saif AL-MAJRFI1 \& Adnan Saleem AL-ABED 2

\begin{abstract}
:
This study aimed to clarify the Effectiveness GeoGebra on Software in Teaching " Space Geometry in the Development of Spatial Abilities and Achievement of Eleventh Grade and tried to answer the following two questions:

1. What is the Effectiveness of using GeoGebra Software in Teaching " Space Geometry of eleventh-grade students?

To answer these questions, a sample of (52) eleventh-grade students was chosen and divided into two groups: an experimental group with (25) students, studied using GeoGebra Software, and a control group with (27) students, studied using the usual way.

To attain the purpose of the study, an educational material for the unit of " Space Geometry " of grade eleven was prepared according to GeoGebra Software Also, GeoGebra Software Achievement test

The study result showed statistically significant differences at the level $(a=0,05)$ between the mean score of the experimental group and the mean score of the control group in the GeoGebra Software Achievement test group who studied using GeoGebra Software.

In light of these results, the study recommended the importance to enter the GeoGebra of anther dynamic program in the math, to study Space Geometry and providing appropriate and encouraging study environment to improve students.
\end{abstract}

Key words: Geogebra, Space Engineering, Software.

\footnotetext{
${ }^{1}$ Researcher, The Ministry of Education, Sultanate of Oman, SSM4144@hotmail.com, https://orcid.org/00000002-0936-3524

2 Prof. Dr. , Sultanate of Oman
}

Copyright (C) Published by IJHER Journal, www.ijherjournal.com

Rimar Academy, Fatih, Istanbul, 34093 Turkey

All rights reserved 


\title{
فاعلية برنامج جيوجبرا (GeoGebra v.5) في اكتساب مفاهيم هندسة الفضاء لاى طلبة الصف الحادي عشر في اكتراب
}

\section{سالم بن سيف بن مبارك المجرفي 3 \\ علنان سليم العابد 4}

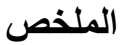

هدفت هذه الدراسة إلى تقصّي فاعلية استخدام برنامج جيو جبرا في اكتساب مفاهيم هندسة الفضاء و القدرات الككانبة لدى طلاب الصف الحادي عشر، وحاولت الإبابة عن السؤ ال التالي: ما فاعلية برنامج جيوجبرا في اكتساب مفاهيم هندسة الفضاء لاى طلبة الصف الحادي

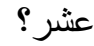
وللإجابة عن هذا السؤال: تم اختير عينة مكونة من (52) طالب من طلاب الصف الحادي

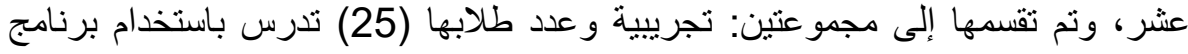

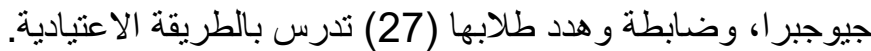

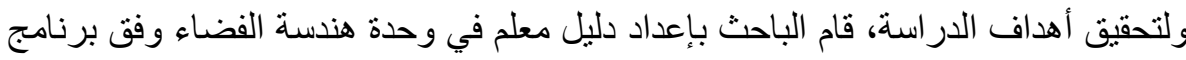
جيوجبرا، كما طبق اختبار تحصيلي.

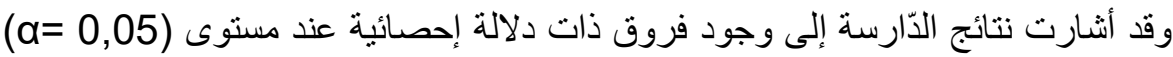

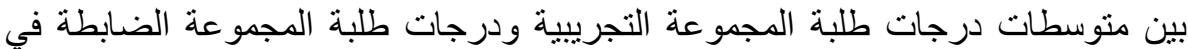

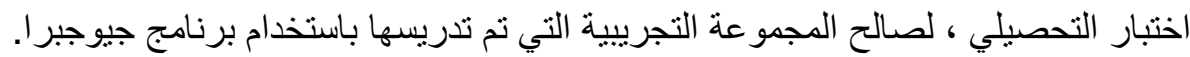

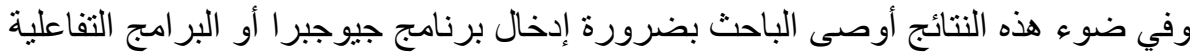

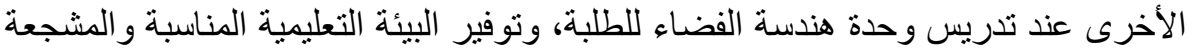

اللطلبة.

الكلمات المفتاحية: البرامج، جيوجبرا، هندة الفضاء.
\end{abstract}

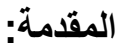

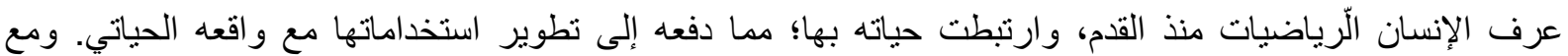
التطور التقني الذي صاحب حياة الإنسان، أصبحت التكنولوجيا شيئًا أساسياً له في شتى مناحي حياته العلمية و العملية؛ لذا لذا

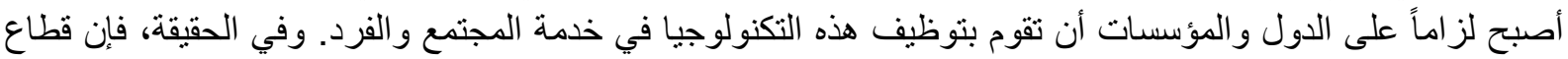
التعليم ليس بمنأى عن هذه التطورات التكنولوجية المتنوعة، فالواقع الحالي يؤكد على أن التكنولوجيا أسهمت في انتشار التعليم بشكل و اسع.

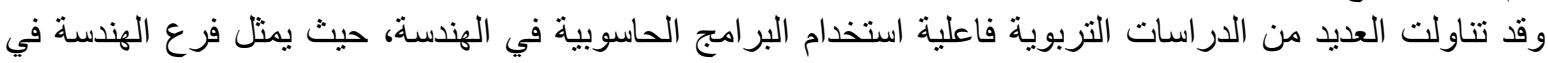
الرياضيات أحد أهم فروع منهج الرياضيات، التي قد يجد الطالب صعوبة في فهم محتواها، أو اكتساب مفاهيمها

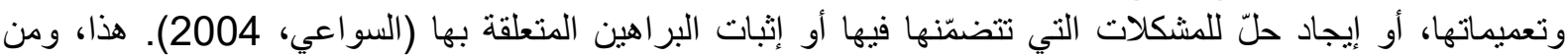

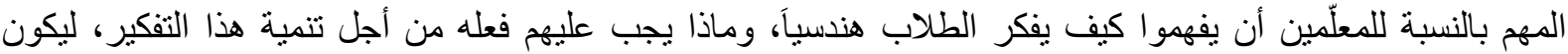

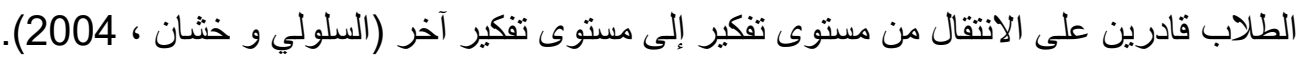

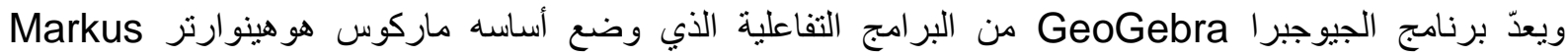
Hohenwarter

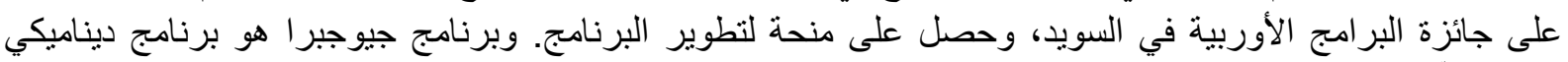

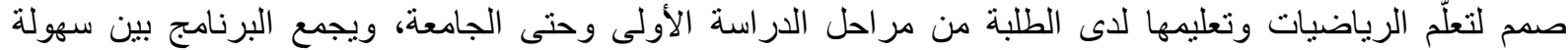

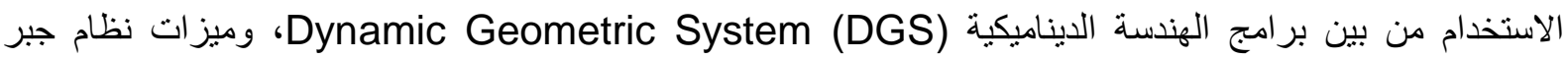


الحاسوب Computer Algebra System (CAS) وبالتالي فإن البرنامج يعمل على ردم الهوة بين فرعي

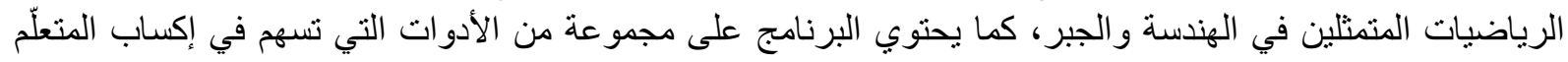

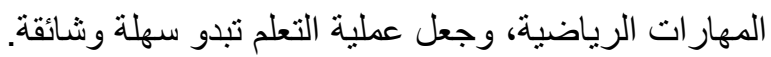

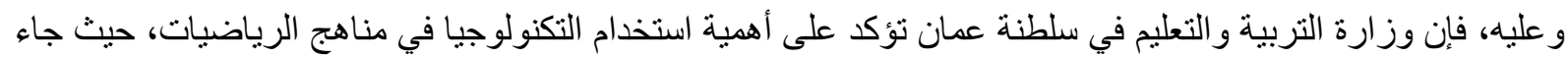

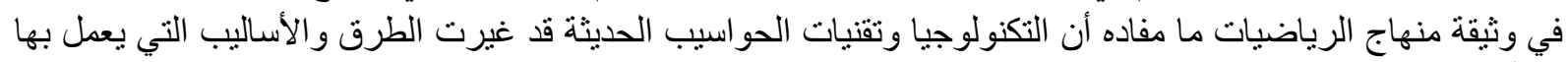

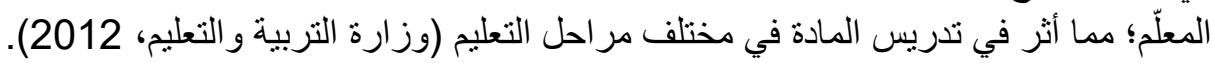

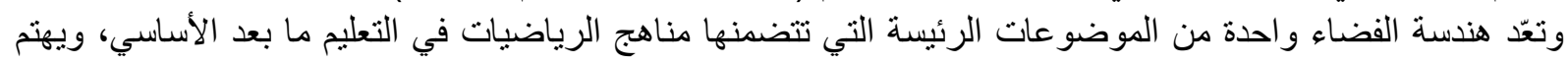

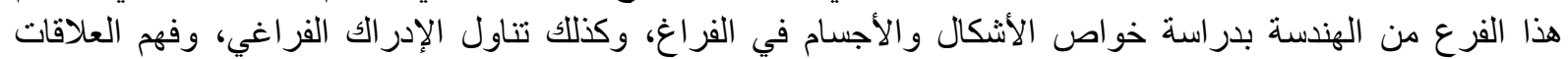
و المصطلحات المستخدمة في وصفها.

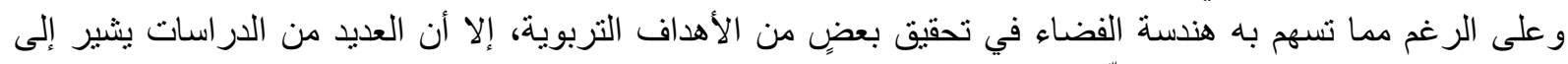

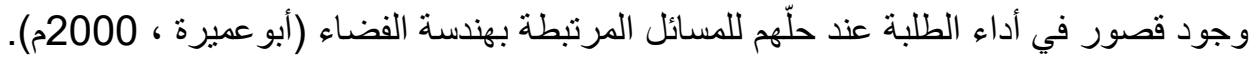

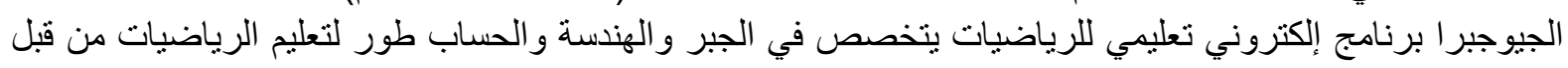

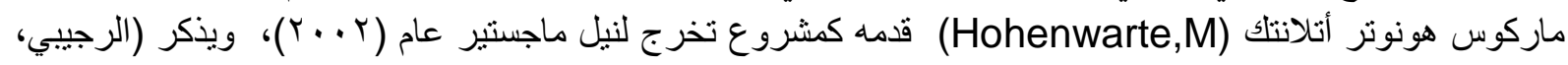

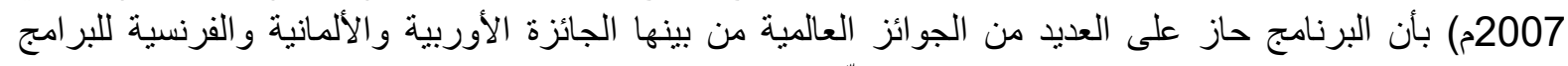

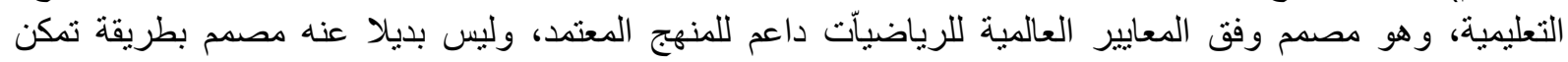

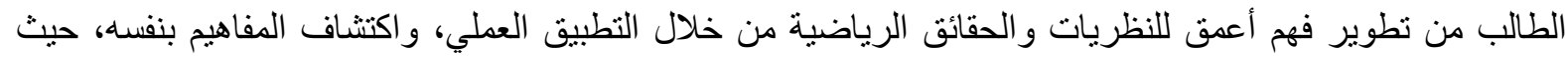

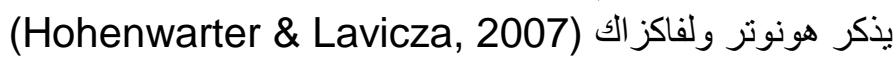

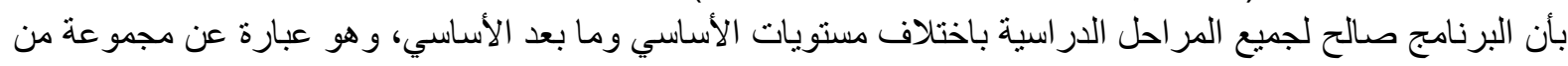

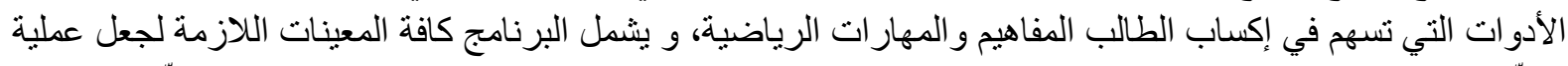

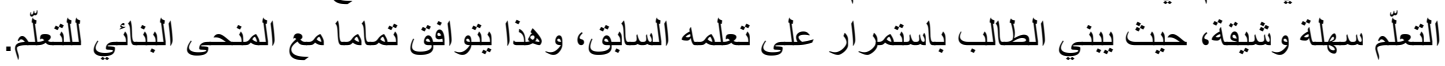

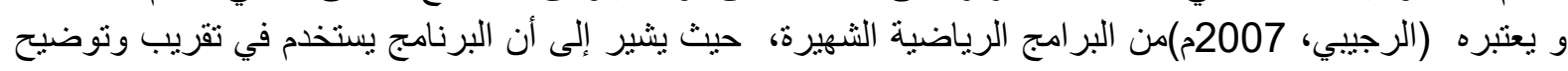

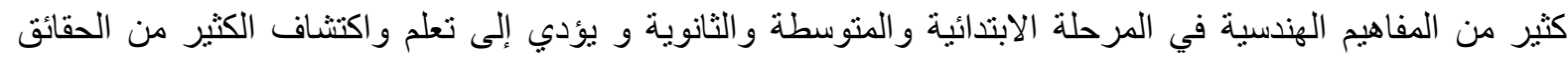

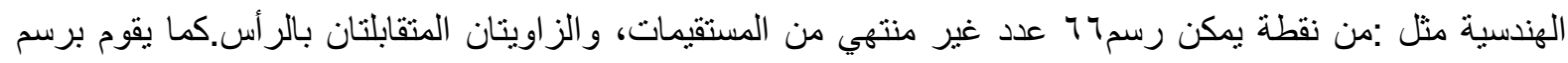

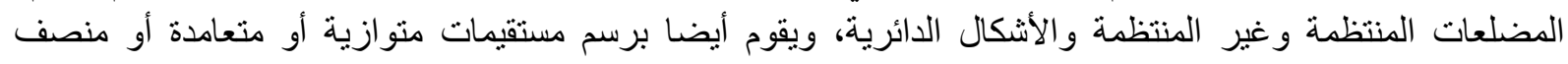

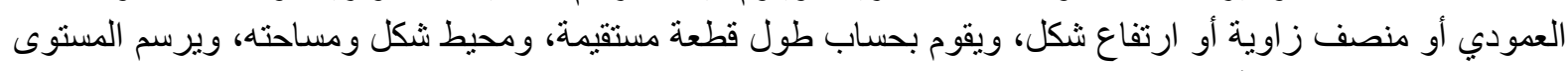

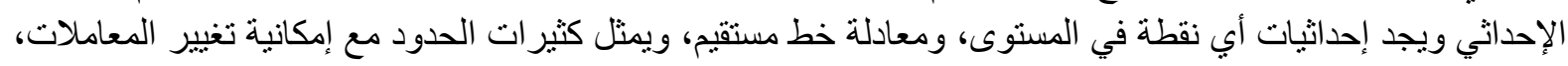

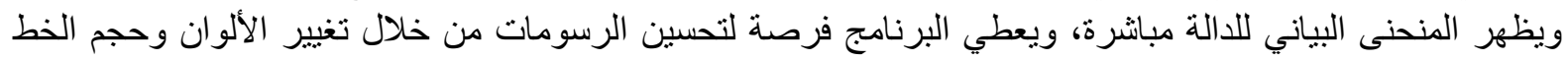
وحجم الرسم أو تحريكه وحفظه.

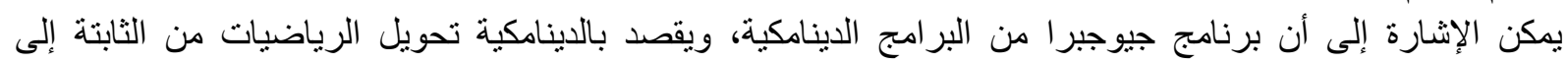

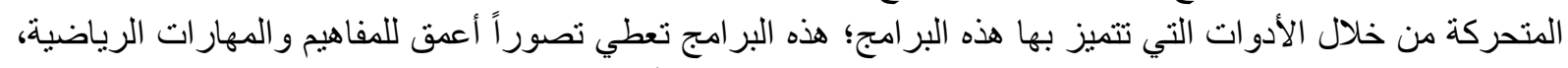

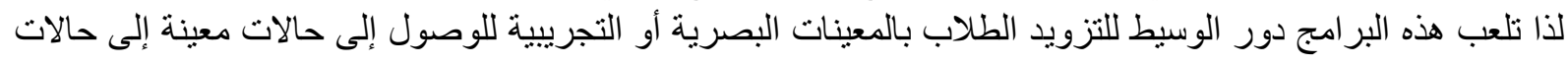

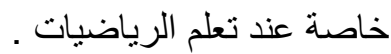
يمكن استخلاص أهم الإمكانيات التي يتميز بها جيوجيرا حسب ما ذكر (البلوي، 2012؛ Hohenwarter \& Fuchs, 2004

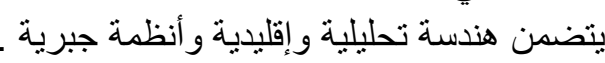
• • رسم الإشكال الهندسية بدقة و إنقان.

إيجاد كافة التحويلات الهندسية.

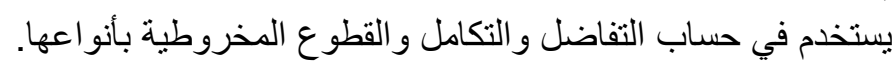

التحكم في نمط الثبكة البيانية وتقسيم المحاور الإحداثية.

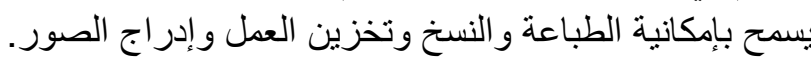

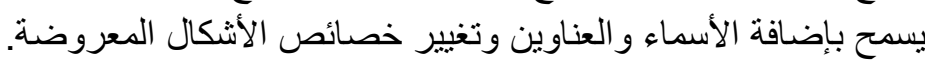
وجود شريط البناء الذي يمكن من خلاله متابعة تطبيق رياضئ واضي معين. 
فقد أجرى (المعري، 2013) دراسة هدفت إلى قياس فاعلية استخدام برنامج جيوجبرا لتدريس مادّة الرياضيات في

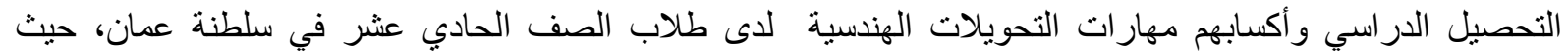

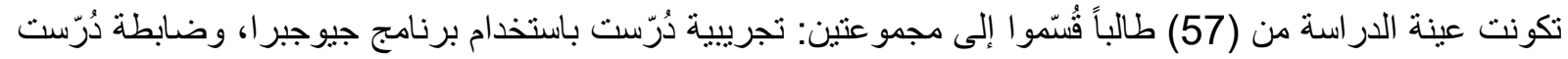

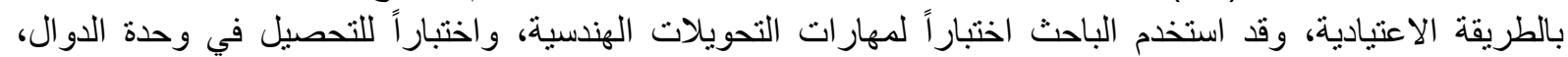

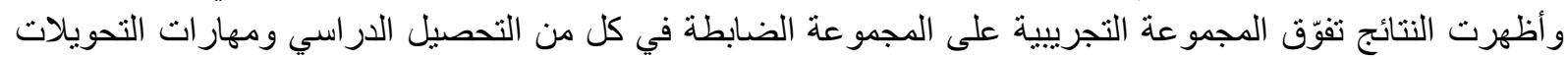

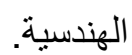

كما أجرى (أبو ثابت، 2013) دراسة هدفت إلى مقارنة ندريس وحدة الدائرة باستخدام برنامج جيوجبرا و الوسائل

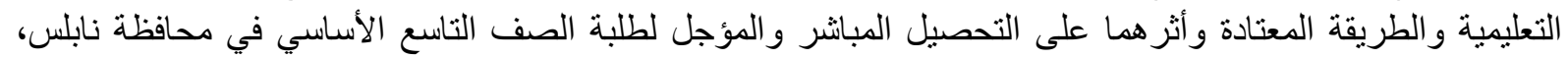

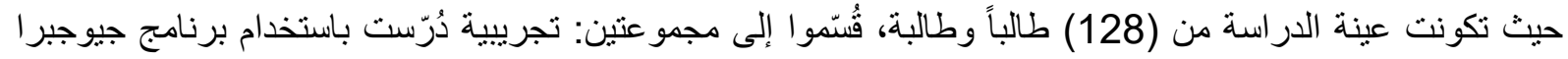

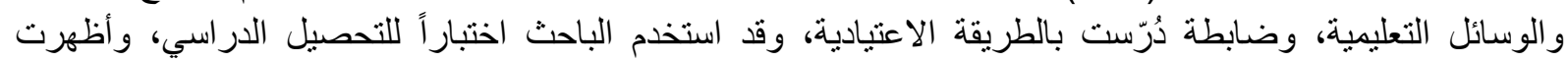

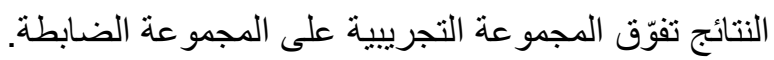

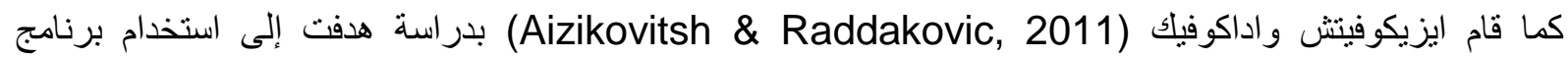

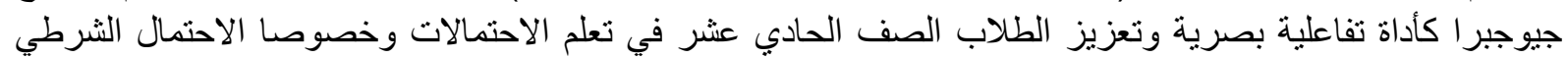

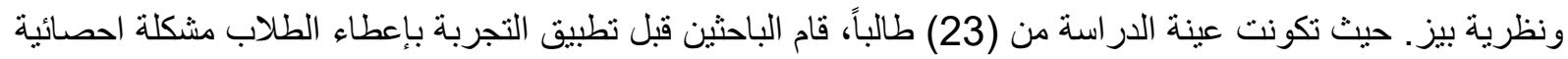

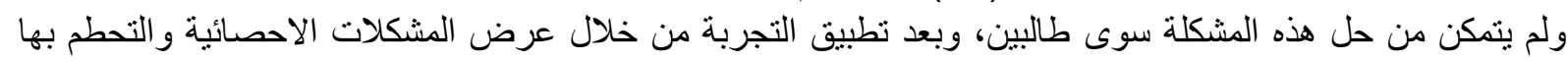

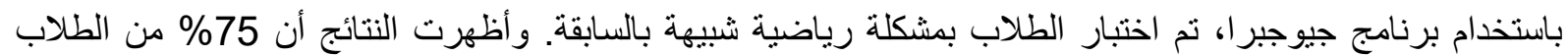
استطاعو ا حل المشكلة التي قدمت لهم. وفي ذات السياق أجرى ميهانوفيك (Mehanovic, 2011) دراسة هدفت إلى قياس فاعلية استخدام برنامج جيوجبرا

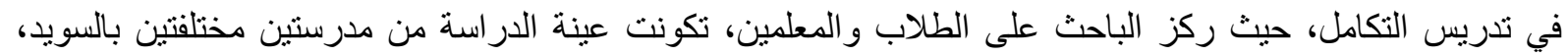

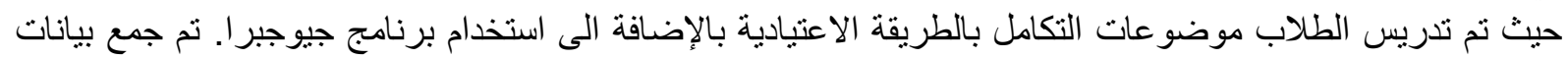

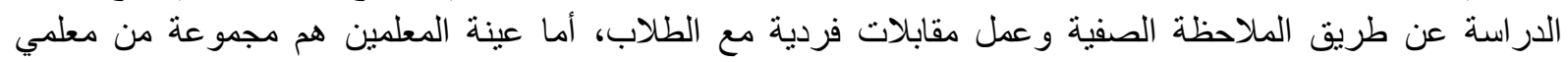

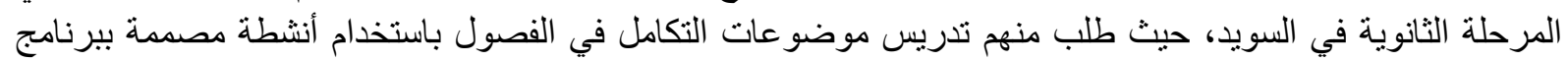

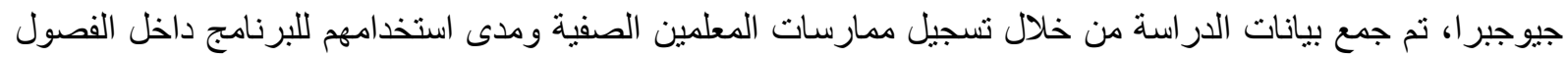

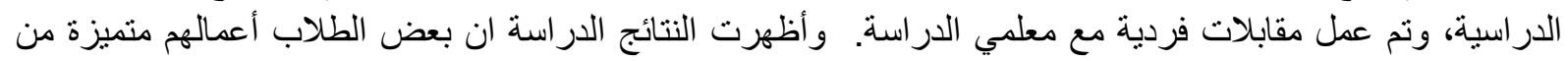

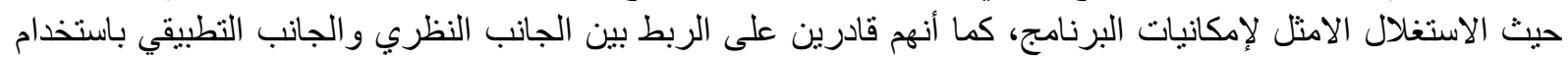

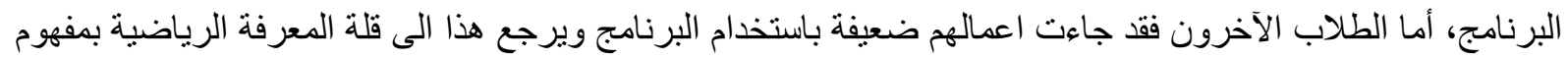

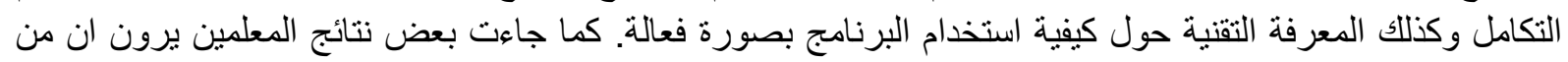

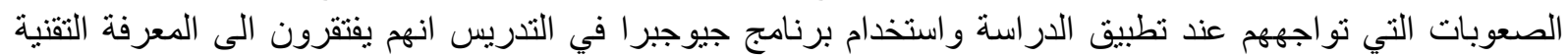

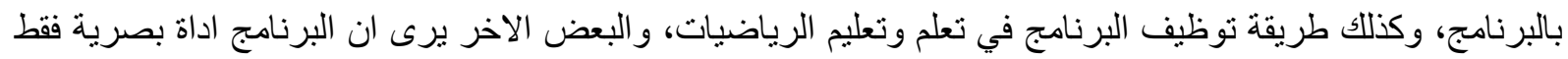

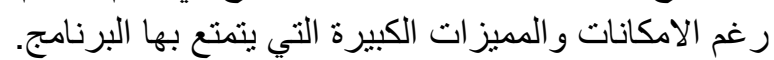

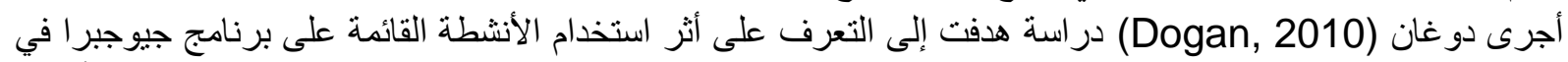

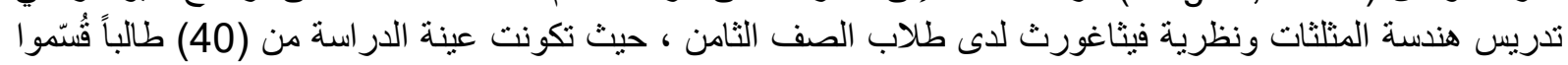

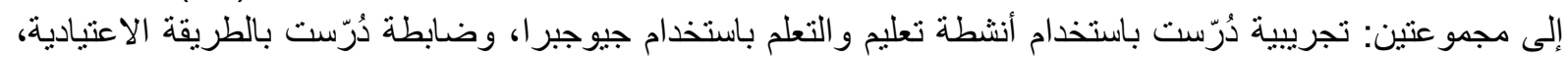

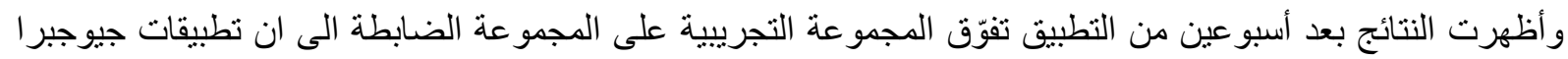
كان لها أثر ايجابي على تعلم الطلبة، وذللك من خلال وجود تحسن في مستوى تحصيلهم وكذللك في اتجاههم نحو تعلم

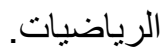
وجاءت در اسة دوكيري (Dockery, 2006) هدفت الدراسة إلى التحقق من أثر تدريس الرياضيات بمساعدة الحاسوب

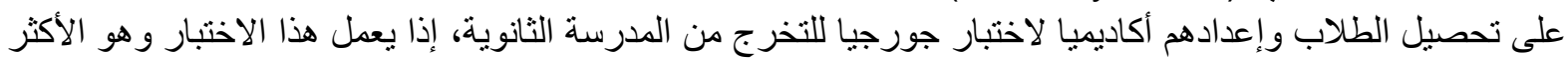

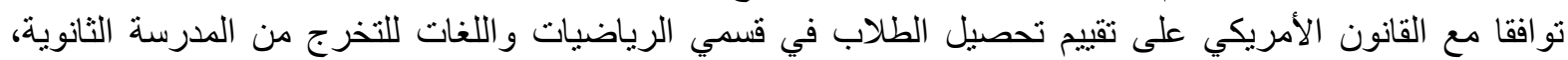

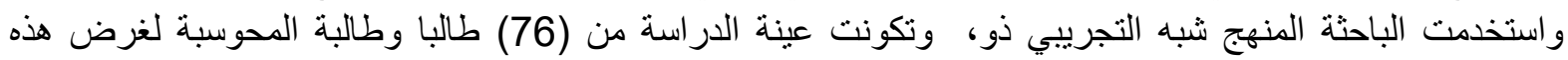

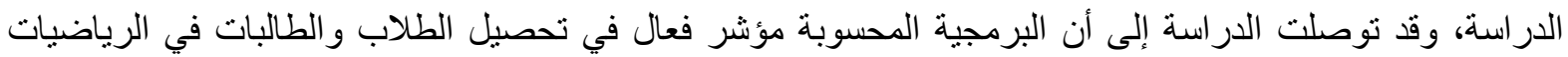

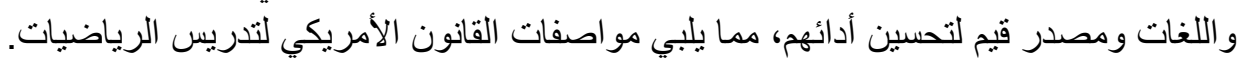




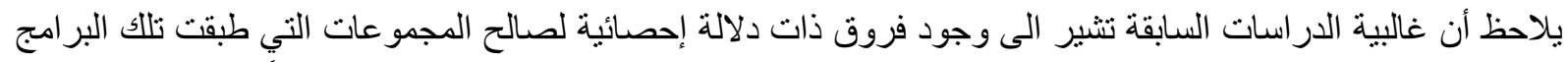

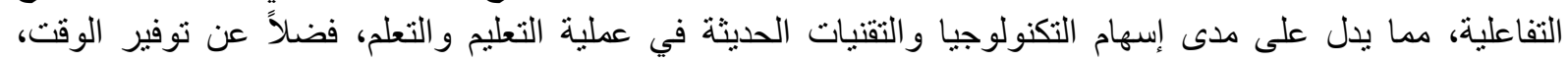

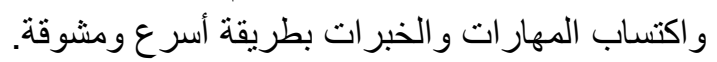

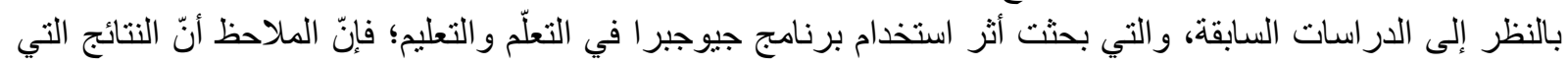

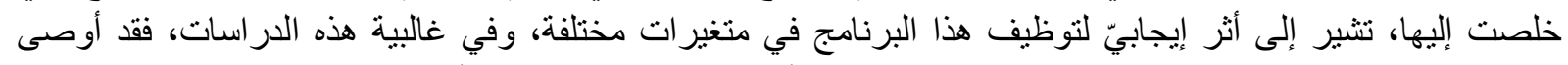

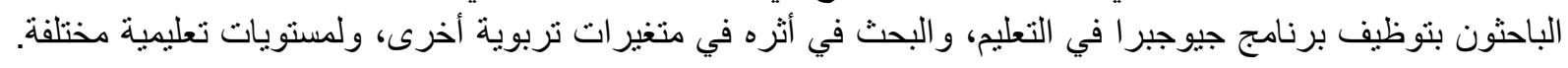

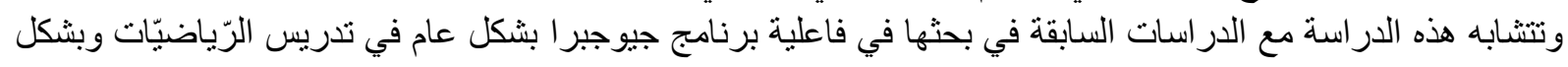
خاص في هندسة الفضاء.

مشكلة الار اسة:

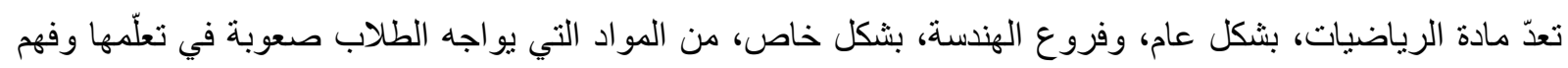

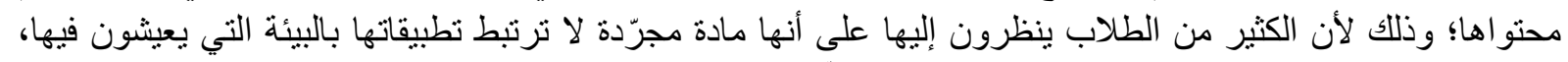

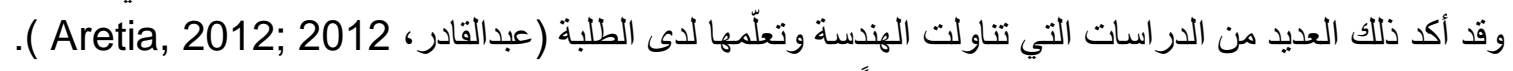

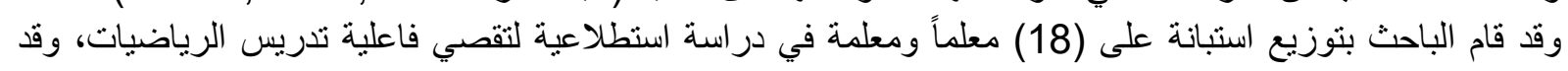

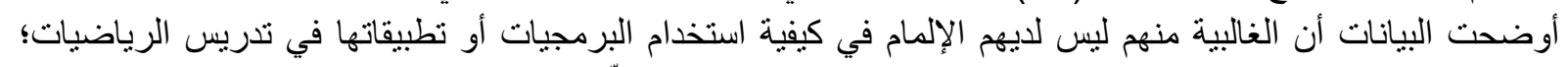

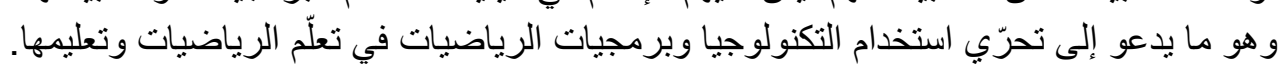

أسئلة الدر اسية: - n

ما فاعلية برنامج جيوجبرا (GeoGebra v.5) في اكتساب مفاهيم هندسة الفضاء لدى طلبة الصف الحادي عشر؟ أهمية الدراسة:

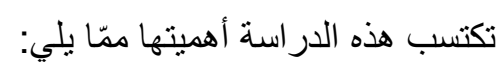

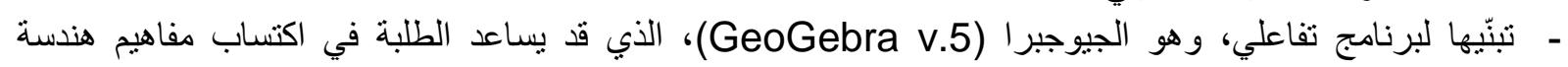
الفضاء. - كونها قد تسهم في مساعدة القائمين على تأليف مناهج الرّياضيّات واختيار هم استر اتيجيات فاعلة في تعلّم الرّياضيّات وتعليمها. - كونها قد تشكّل حافزاً للباحثين في مجال تعلّم الرّياضيّات وتعليمها؛ للبحث في أثر استخدام هذا البرنامج في متغيرات أخرى ولمر احل تعليمية مختلفة.

حدود الاراسة ومحدّداتها:

يمكن تعميم نتائج هذه الدر اسة في ضو اء الحدود و المحدّدات الآتية:

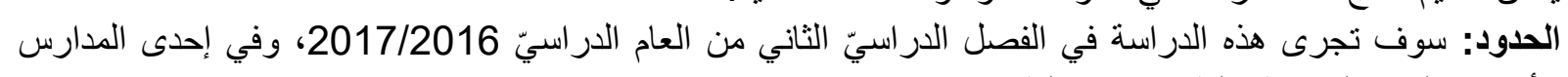
الأساسيّة التابعة لمحافظة الظاهرة في سلطنة عمان.

المحدّدات:

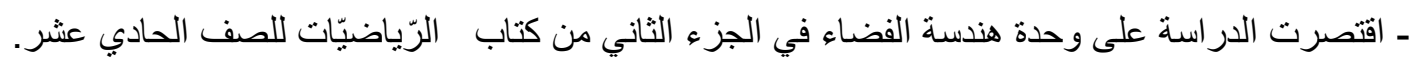

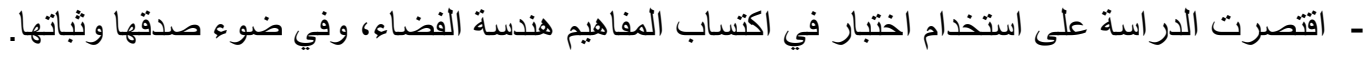
- م اقتصرت الدراسة على طلبة الصف الحادي عشر. 
تناولت الدراسة المصطلحات الآتية: ـ اكتساب المفاهيم: قدرة الطالب على فهم الخصائص المشتركة لمجمو عة من العناصر الرياضيّة المرتبطة في إطار موحد

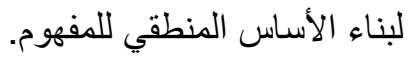

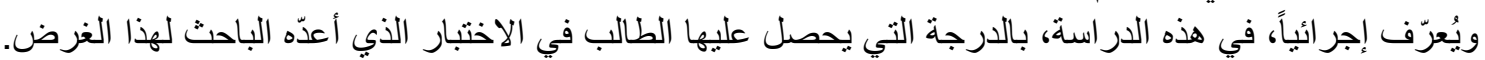

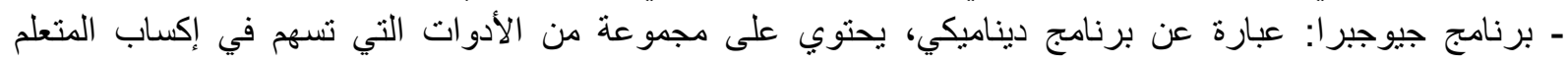
المهار ات الرياضية.

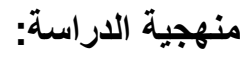

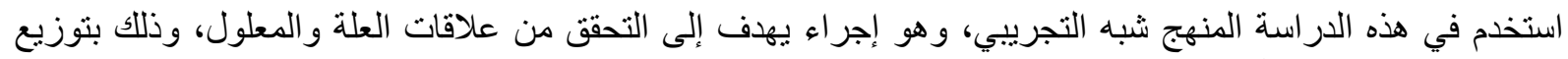

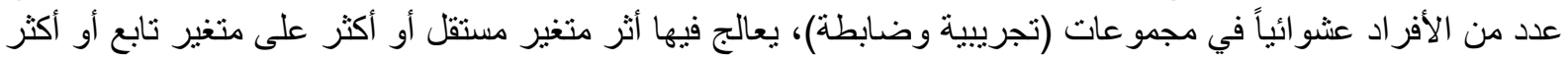

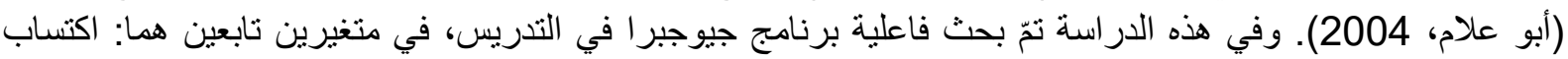
المفاهيم الرياضيّة، القدر ات المكانية.

أفراد الدراسة:

بلغ عدد افر اد الدراسة (52) طالباً من طلاب الصف الحادي عشر ،الحادي عشر (1) و عدد الطلاب فيها (27) طالباً، و الحادي عشر(3) و عدد الطلاب فيها (25) طالباً، ثم لجأ الباحث إلى الطريقة العشوائية البسيطة لتمثيل الثعبتين

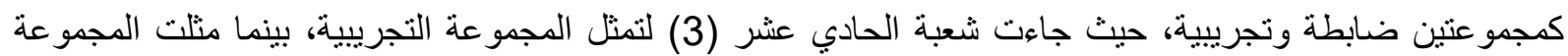
الضابطة شعبة الحادي عشر (1)، و الجدول (1) يوضح نوزيع أفر اد الدراسة في المجمو عتين التجريبية والضابطة، وعدد

أفر اد كل منهما.

\begin{tabular}{|c|c|c|}
\hline عدد الطلاب & الصفي التجريبية و ال & المجموزيع أفر \\
\hline 25 & الحادي عشر (3) & التجريبية \\
\hline 27 & الحادي عشر (1) & الضـابطة \\
\hline 52 & & المجموع \\
\hline
\end{tabular}

أدوات الاراسة:

لتحقيق أهداف الدر اسة، تمّ إعداد اختبار تحصيلي.

تصميم الاراسة:

الدراسة الحالية شبه تجرييية، وتم اتباع المنهج شبه التجريبي من خلال اختبار مجموعتين تجريبية وضابطة من طلبة

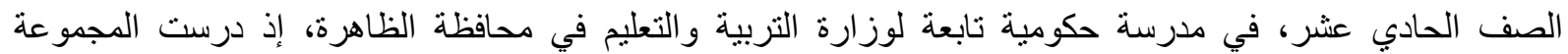
التجريبية وحدة هندسة الفضاء وفق برنامج جيوجبر ا، ودرست المجموعة الضابطة الوحدة نفسها وفق الطريقة الاعتيادية.

EG: $\quad 0102 \quad \mathrm{O} \quad 0102$

واعتمد التصميم التالي في هذه الاراسة:

CG: $\mathrm{O} 1 \mathrm{O} 2 \quad-\quad \mathrm{O}$ O2

حيث أن:

EG

CG

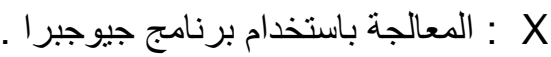




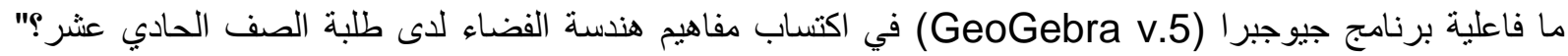

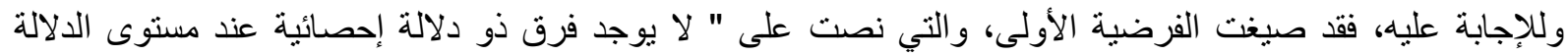

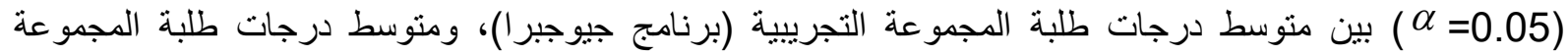
الضابطة (الطريقة الاعتيادية)، في اختبار اكتساب مفاهيم هندسة الفضاء.

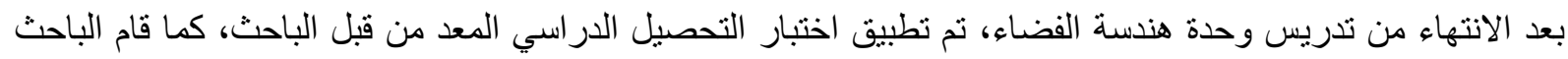

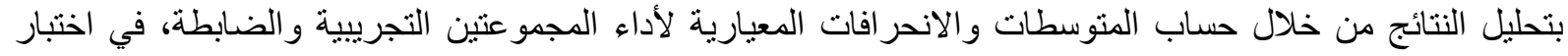

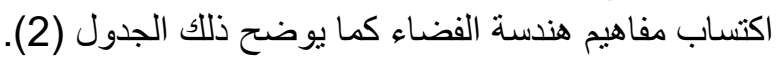

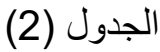

المنوسطات الحسابية و الانحر افات المعيارية لدرجات الطلاب في المجمو عتين التجريبية و الضابطة في اختبار اكتساب مفاهيم هندسة الفضاء (القبلي والبعدي)

\begin{tabular}{|c|c|c|c|c|}
\hline \multicolumn{2}{|c|}{ الاختبار التحصيلي (البعدي) } & \multicolumn{2}{|c|}{ الاختبار التحصيلي (القبلي) } & \multirow{2}{*}{ المجمو عة } \\
\hline الضـابطة & التجريبية & الضابطة & التجريبية & \\
\hline 3.24 & 18 & 9.01 & 9.23 & المتوسط الحسابي \\
\hline 3.29 & 3.24 & 2.15 & 2.25 & الانحر اف المعياري \\
\hline
\end{tabular}

يتضح من الجدول (2) وجود فروق ظاهرية بين متوسطات درجات طلاب المجموعتين التجرييية والضابطة على اختبار

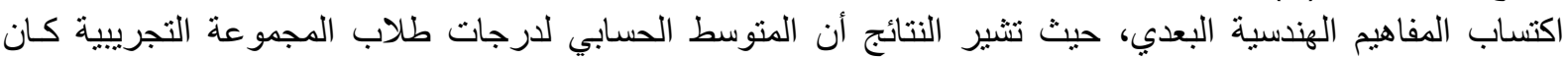

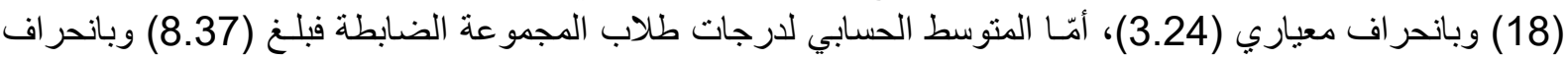

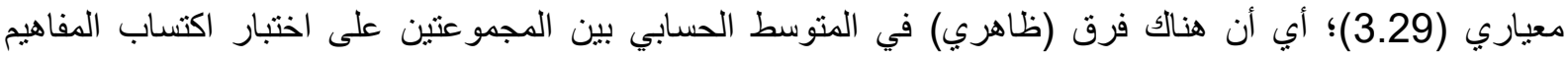
الهندسية البعدي مقداره (9.63)، لذا يتضح من الجدول (2) وجود دلالة إحصائية للفرق بين منوسطي درجات طيلات

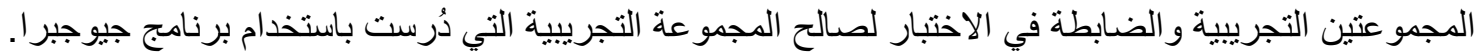

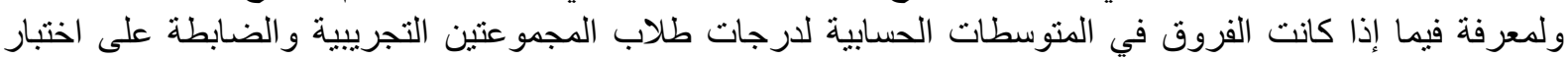

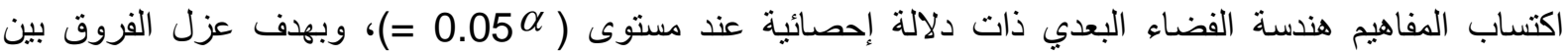

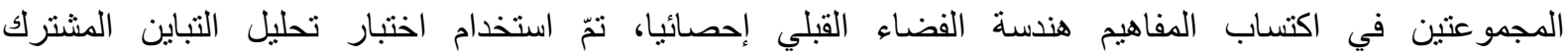
(ANCOVA)

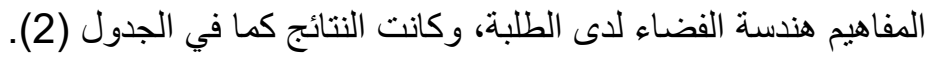

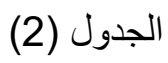
نتائج تحليل التباين المثترك (ANCOVA) لدرجات الطلاب في المجمو عتين التجريبية والضابطة على اختبار اكتساب المفاهيم هندسة الفضاء البعدي

\begin{tabular}{|c|c|c|c|c|c|c|}
\hline |المستقل م2 لأثر المتغير & الدلالة & الميمة & متوسط & لرجات & |لمربعوع & سدر التباين \\
\hline 0.012 & 0.446 & 0.592 & 6.373 & 1 & 6.373 & الاختبار القبلي \\
\hline \multirow[t]{3}{*}{0.676} & 0.0000 & 102.462 & 1103.932 & 1 & 1103.923 & المجمو عة \\
\hline & & & 10.774 & 49 & 527.923 & الخطأ \\
\hline & & & & 52 & 10526 & الكلي \\
\hline
\end{tabular}

تشير النتائج في الجدول (2) إلى وجود فروق دالة إحصائياً بين منوسطات درجات الطلاب في المجموعتين الضابطة

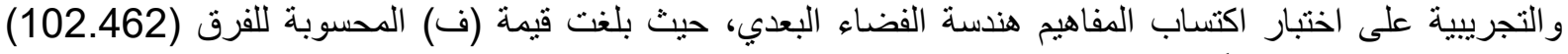

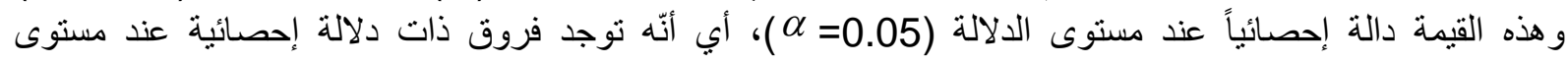




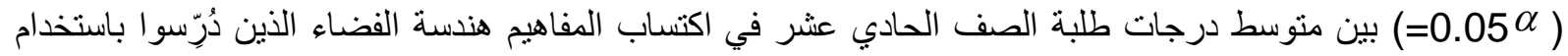

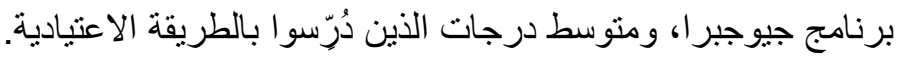

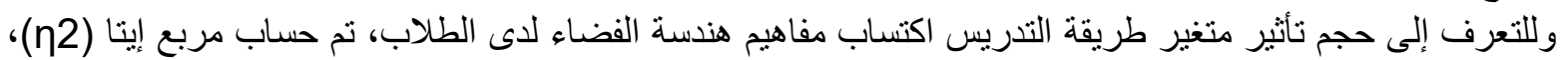
وقد بلغت قيمة مربع إيتا في اختبار مفاهيم هندسة الفضاء

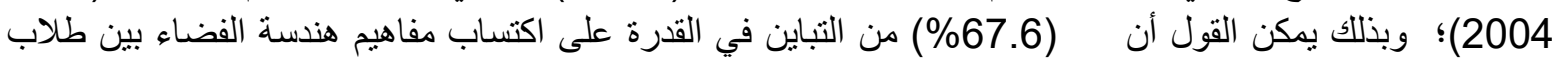
المجمو عتين التجريبية و الضابطة برجع لمتغير طريقة التدريس المستخدمة.

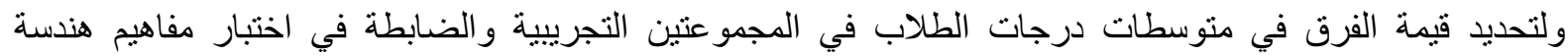

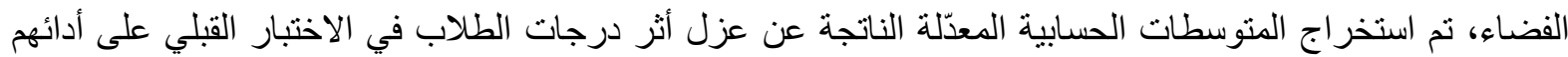
في اختبار البعدي، وكانت النتائج كما في الجدول (3) الندات

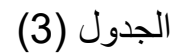
المتوسطات الحسابية المعلة لدرجات الطالبات في المجموعتين التجريية والضابطة على اختبار اكتساب مفاهيم هندسة الفضاء

\begin{tabular}{|c|c|c|}
\hline الخطأ المعياري & المتوسط الحسابي المعدل & المجموعة \\
\hline 0.666 & 17.916 & التجريبية \\
\hline 0.640 & 8.449 & الضابطة \\
\hline
\end{tabular}

تشير نتائج المتوسطات الحسابية المعدلة لدرجات الطالبات في المجموعتين التجريبية والضابطة على اختبار اكتساب

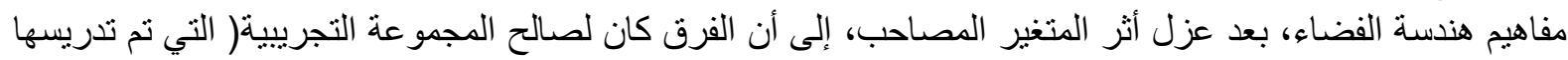

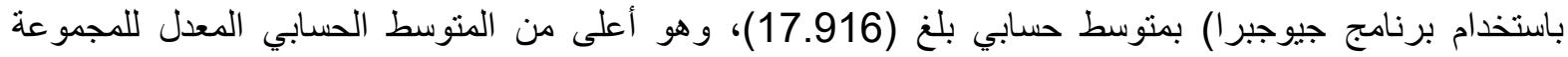

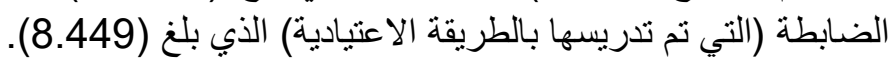

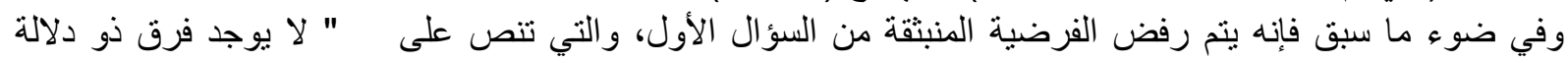

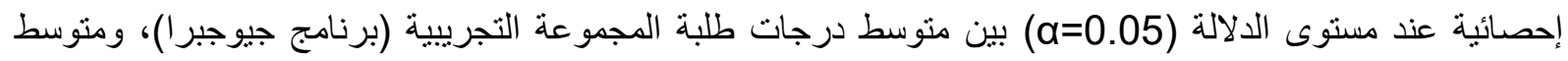

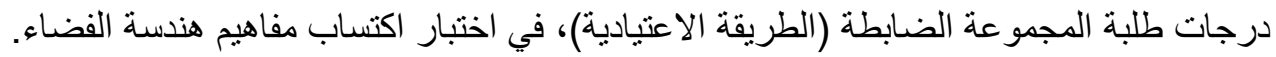

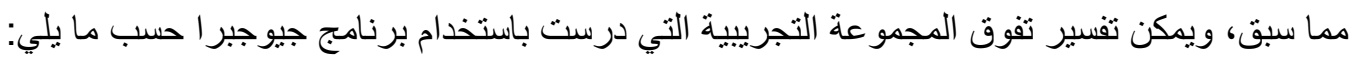

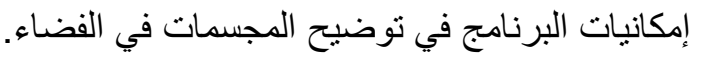

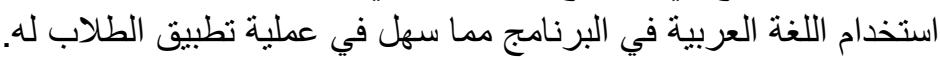

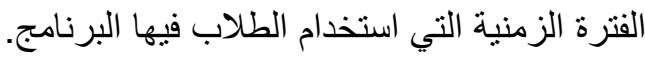

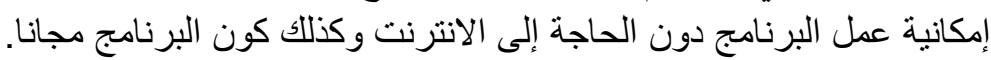

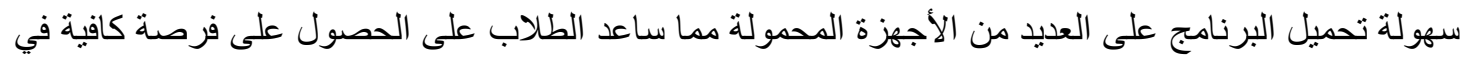
التعلم الذاتي مما ساعد على زيادة تحصيل الطلاب في هذه الونيد الوحدة.

التوصيات:

بناءً على نتائج هذه الدر اسة، يوصي الباحث بما يأتي:

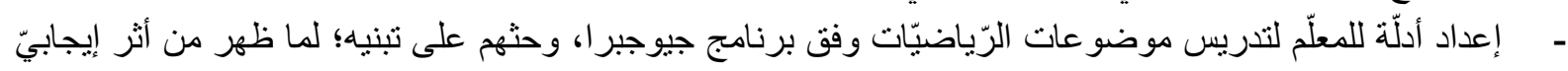
لاستخدامه.

عقد دورات تدريية للتعريف بهذا البرنامج و إمكانياته، وتدريب المعلمين على استخدامه وتوظيفه في التدريس.

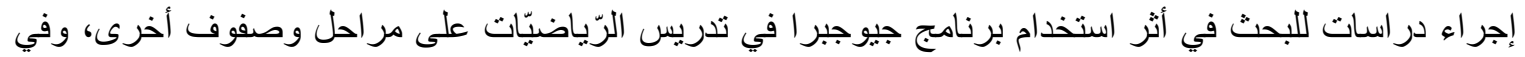
موضو عات غير الهندسة.

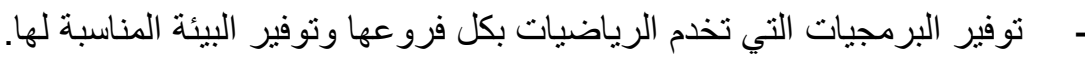
توجيه المشرفين التربويين إلى أهمية متابعة وتثجيع معلمي الرياضيات على التى استخدام البرامج التفاعلية ومنها جيوجبر ا. - إدر اج بعض الأمثلة للاروس المصممة باستخدام برنامج جيوجبرا في أدلة المعمين ضمن مناهج الرياضيات من أجل أن بتسنى للمعلمين تصميم دروس مشابهة. 


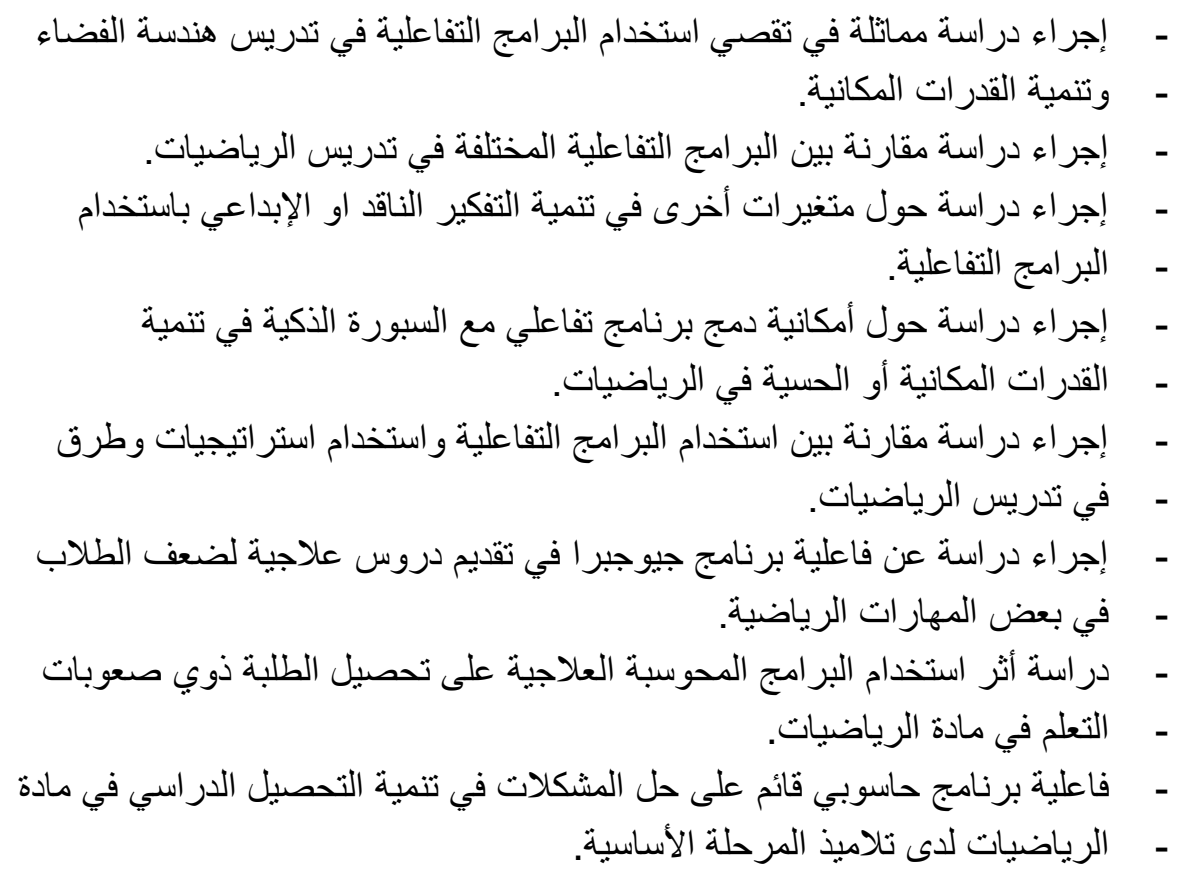

المراجع

اجتياد عبدالرزاق حامد أبو ثابت. (2013). مدى فاعلية استخدام برنامج جيوجبرا و الوسائل التعليمية في التحصيل

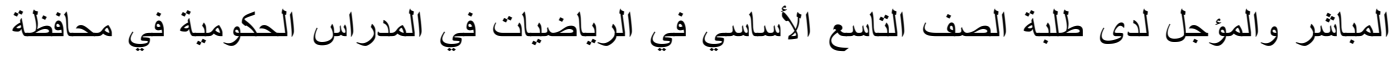

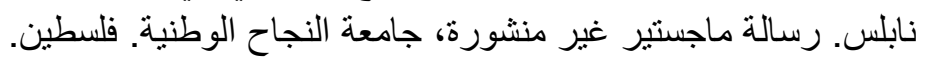

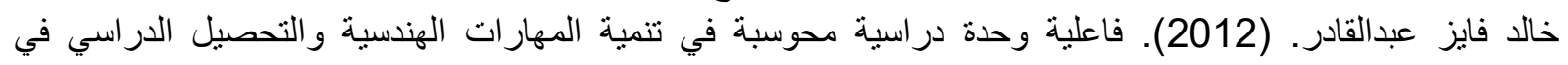

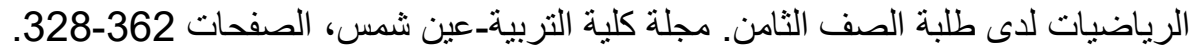

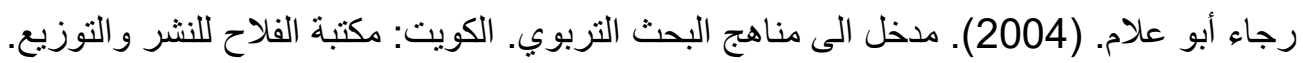

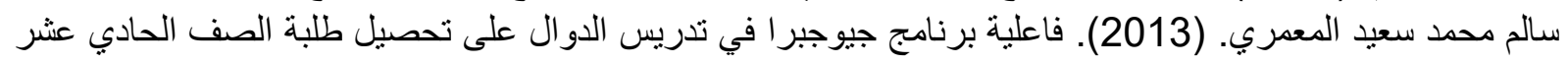
و إكسابهم دهارات التحويلات الهندسية ـ رسالة ماجستير غير منشورة،جامعة السلطان قابوس. سلطنة عمان.

عايد محدد علي البلوي. (2012). برنامج تدريبي قائم على البرامج التفاعلية في تعليم الرياضيات وتعلمها. رسالة

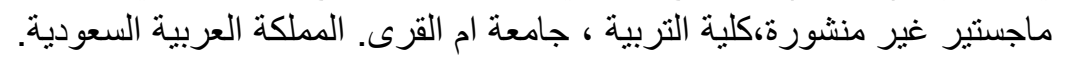

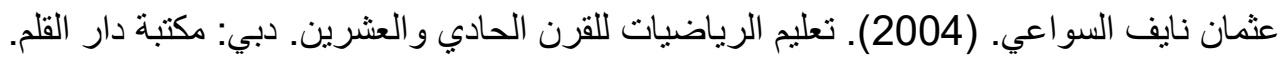

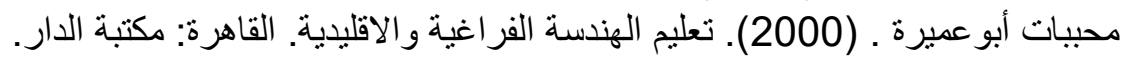

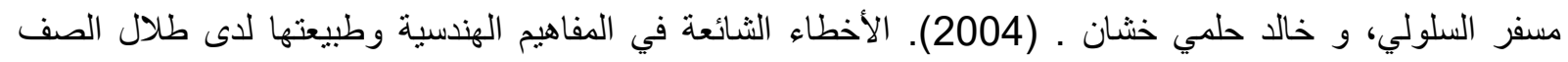

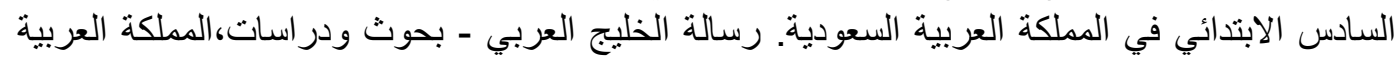

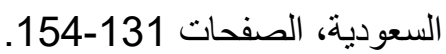

وزارة التربية والتعليه. (2012). وثيقة منهاج الرياضيات. سلطنة عمان. يوسف بن خلفان الرجيبي. (2007). (207). برنامج الرياضيات GeoGebra. مجلة التنطوير التربوي: سلطنة عمان.العدد 37، الصفحات 26-26.

A. E., \& R. N. (2011). Using GeoGebra for Understanding and Supporting Students' Learning of Probability. Proceeding of the Second North American GeoGebra Conference: Where Mathematics, Education and Technology Meet. Canade: University of Toronto. 
Aretia, P. (2012). Young Students self-Beliefs About Using Representaion In Relation To The Geometry Understanding. assistant professor in mathematics education, Frederick university.

Dockery, J. (2006). The Effectiveness of Computer-Assisted Instruction in Preparing Academically At-Risk Students for the Georgia High School Graduation Test. Dissertation Abstract International, Capella University,, USA, AAT 32160.

Dogan, M. (2010). ). Effect of Using GeoGebra on Students' Success: An Example about Triangles. First Euroasia Meeting of GeoGebra (EMG).TC Istanbul University, Turkey.

H. M., \& L. Z. (2007). Mathematics Teacher Development with ICT: Towards an International GeoGebra Institute. Proceedings of the British Society for Research into Learning Mathematics, p. 27.

Hohenwarter, M., \& Fuchs, K. (2004). Combination of Dynamic Geometry, Algebra and Calculus in the Software System GeoGebra. Retrieved from http://wiki.geogebra.org/en/Publications.

M. S. (2011). The Potential and Challenges of the Use of Dynami Software in Upper Secondary Mathematics: Students' and Teacher' Work With Integrals in GeoGebra Based Environments. Unpublished Licentiate Thesis, Linkoping University, Sweden. 